\title{
Effect of Tiny Pd Addition to Ti for Their Hydrogenation Properties
}

\section{Ryota KONDO* and Hiroyuki T. TAKESHITA}

Dept. of Chemistry and Material Engineering, Kansai University3-3-35, Yamate-cho, Suita 5648680, Japan

”rkondo@kansai-u.ac.jp

Keywords: Hydrogen storage, Initial activation, Catalyst, Ti-Pd.

\begin{abstract}
Titanium (Ti) based hydrogen-storage materials can absorb hydrogen under mild conditions. However, the materials could not absorb hydrogen without initial activation, owing to the formation of surface oxide layer. For mitigate the initial activation conditions, addition of $\mathrm{Pd}$ to Ti based materials were conducted. In spite of a tiny content of Pd, the addition was effective. In this study, effect of $\mathrm{Pd}$ in $\mathrm{Ti}$ oxide layer on initial hydrogenation property was investigated. $\mathrm{Ti}_{(1-\mathrm{x})}$ $\operatorname{Pd}_{x}(x=0,0.002,0.005,0.010)$ alloys were fabricated with an arc-melting machine in an $\mathrm{Ar}$ atmosphere. Turnings-like specimens were obtained by milling the ingots with a milling machine for increase of specific surface. Initial hydrogenation properties were carried out with a Sievertstype apparatus. Surface property of $\mathrm{Ti}_{0.990} \mathrm{Pd}_{0.010}$ before hydrogenation was carried out by X-ray photoelectron spectroscopy. Pd-added Ti alloys rapidly formed Ti hydride compared with pure Ti. $\mathrm{Pd}$ in the oxide film existed as valence state of $0\left(\mathrm{Pd}^{0}\right)$. Because metallic $\mathrm{Pd}$ was well-known as catalyst for dissociation of molecular hydrogen, Pd-added Ti alloys can faster absorb hydrogen.
\end{abstract}

\section{Introduction}

Greater use of renewable energy and energy efficiency, hydrogen storage materials such as transition metals and complex hydrides (i.e. $\mathrm{LaNi}_{5}, \mathrm{TiFe}, \mathrm{LiBH}_{4}$ and so on) has been studied to achieve hydrogen society. In particular, Ti-based hydrogen storage material is a low price and can absorb and desorbs hydrogen at low pressure and temperature[1-3]. Concerning the advantages of the Ti-based hydrogen storage material, it could be practical and affordable for stationary applications [4-6]. In general, the series need initial activation at high temperature in hydrogen or a vacuum due to their stable passive oxide film which was formed after exposing in air[7-9]. After initial activation, the oxide film cracked and/or reduced followed by exposing of active surface[10].

Several challenges have been attempted to mitigate the initial activation conditions. For example, addition of catalytically active element, Pd was effective for mitigation of initial activation despite a tiny content $[11,12]$.

Thus in this study, surface property of Ti alloys with a tiny amount of Pd was investigated by using X-ray photoelectron spectroscopy (XPS).

\section{Experimental Methods}

Pure Ti buttons were prepared by arc-melting from sponge Ti (99.7mass\%) prior to obtaining Ti-Pd alloys for purifying $\mathrm{Ti}$. $\mathrm{Ti}_{(1-\mathrm{x})} \mathrm{Pd}_{\mathrm{x}}(\mathrm{x}=0.002,0.005,0.010)$ alloys were arc-melted to form buttons from the pure Ti buttons and Pd sheet (99.95mass\%) in an Ar atmosphere on a water-cooled cupper hearth. Each alloy was re-melted at least ten times to promote the homogeneity of the composition. A turnings-like specimen was obtained by milling the ingots with a milling machine. A plate type specimen for XPS was prepared by cutting using an abrasive cutting machine followed by mechanical polishing with waterproof $\mathrm{SiC}$ papers from \#320 to \#800 and $0.04 \mathrm{~m}$ colloidal silica suspensions with ultrapure water. After mechanically polished, the specimens were immediately cleaned at least three times with ultrasonic cleaning machine in acetone for c.a. $600 \mathrm{~s}$. Both turnings and plates were stored in an auto-dry desiccator at least $86.4 \mathrm{ks}$ for stabilizing surface oxide film. 
Hydrogenation property before activation was examined with a Sieverts-type apparatus under the conditions of initial hydrogen pressure of 3.0 MPa at R.T., heating at $5 \mathrm{~K} \mathrm{~min}^{-1}$ to $673 \mathrm{~K}$, and 500 $\mathrm{mg}$ of sample quantity in a stainless steel reactor. Phase identification for before and after hydrogenation was performed using an X-ray diffract meter (XRD) with CuK irradiation at tube voltage of $30 \mathrm{kV}$ and tube current of $15 \mathrm{~mA}$. XPS was performed using AlKa radiation at 1486.6 $\mathrm{eV}$ as the excitation source. The take-off angle for photoelectron detection was 45 degree from the surface of the plates. To estimate the photoelectron peak intensities, the background was subtracted from the measured spectrum according to the Shirley's method and peak fitting and integration of XPS spectra were analyzed using a commercial software package (Casa-XPS). Depth profiles were obtained using Ar gas sputtering with an equivalent $\mathrm{SiO}_{2}$ sputtering rate of $1.2 \mathrm{~nm} \mathrm{~min}{ }^{-1}$.

\section{Results and Discussion}

After hydrogen introduced and the reactor was heated, hydrogen was slightly absorbed during c.a. 0.3 in H/M subsequent drastic absorption took place. To reveal a reaction of the drastic hydrogen absorption, the samples were taken out from the stainless steel reactor before and after the time at which drastic change in hydrogen absorption rate was observed in the figure and phase constitutions of the two samples were investigated by XRD. Before the point, the sample was composed of only - Ti, whereas the sample transformed to Ti hydride (TiH1.924) after the time. Pd added Ti has a feature of rapid transformation for Ti hydride compared with Ti.

The XPS profiles of Ti $2 p$ from mirror-polished Ti and $\mathrm{Ti}_{0.990} \mathrm{Pd}_{0.010}$ showed that $\mathrm{Ti} 2 \mathrm{p}$ spectra of $\mathrm{Ti}$ and $\mathrm{Ti}_{0.990} \mathrm{Pd}_{0.010}$ divided for peaks from valence state of $0\left(\mathrm{Ti}^{0}\right), 2\left(\mathrm{Ti}^{2+}\right), 3\left(\mathrm{Ti}^{3+}\right)$ and $4\left(\mathrm{Ti}^{4+}\right)$ and the spectra of $\mathrm{Ti}$ was in a good agreement with $\mathrm{Ti}$ alloy after exposed under air for c.a. 1 week[13]. Comparing pure $\mathrm{Ti}$ with $\mathrm{Ti}_{0.990} \mathrm{Pd}_{0.010}$, the peak from $\mathrm{Ti}^{0}$ was not detected from $\mathrm{Ti}_{0.990} \mathrm{Pd}_{0.010}$ despite of the peak detection from pure Ti. Ti $2 \mathrm{p}$ spectra of $\mathrm{Ti}$ and $\mathrm{Ti}_{0.990} \mathrm{Pd}_{0.010}$ after argon gas sputtered for 300s. The peaks between that from $\mathrm{Ti}$ and $\mathrm{Ti}_{0.990} \mathrm{Pd}_{0.010}$ indicated obviously different results. The intensity of $\mathrm{Ti} 0$ of $\mathrm{Ti}$ was higher than that of $\mathrm{Ti}_{0.990} \mathrm{Pd}_{0.010}$. These results imply the thickness of $\mathrm{Ti}$ oxide layer of $\mathrm{Ti}_{0.990} \mathrm{Pd}_{0.010}$ was thicker than that of $\mathrm{Ti}$.

Thick oxide film was formed on $\mathrm{Ti}_{0.990} \mathrm{Pd}_{0.010}$ compared with that on $\mathrm{Ti}$. The oxide film was retard to hydrogenation due to low hydrogen diffusion rate[14]. From theoretical calculation, the density of states near the Fermi level of solid solution state Pd increased followed by acceleration of oxidation due to formation of cathodic surface $[15,16]$. In addition the formation of thick oxide film on $\mathrm{Ti}_{0.990} \mathrm{Pd}_{0.010}$ was good agreement in enhancement of corrosion resistance[17, 18]. Therefore it could be considered that the $\mathrm{Ti}_{0.990} \mathrm{Pd}_{0.010}$ rapidly transformed into Ti hydride because valence state of $\mathrm{Pd}^{0}$ could dominantly work as catalyst for dissociation of molecular hydrogen.

\section{Conclusions}

In this study, effect of Pd in Ti-Pd alloys for initial hydrogenation property and surface property was investigated. $\mathrm{Pd}$ existed as valence state of $\mathrm{Pd}^{0}$ in oxide film on $\mathrm{Ti}_{0.990} \mathrm{Pd}_{0.010}$ and the oxide film was thicker than that of $\mathrm{Ti}$. Hydrogenation of $\mathrm{Ti}_{0.990} \mathrm{Pd}_{0.010}$ was rapidly occurred compared with that of $\mathrm{Ti}$ whereas the formation of thick oxide film on $\mathrm{Ti}_{0.990} \mathrm{Pd}_{0.010}$. Therefore, the rapid hydrogenation in $\mathrm{Pd}$ added $\mathrm{Ti}$ alloys could dominantly account for formation of significant dissociated hydrogen atom on the surface due to $\mathrm{Pd}^{0}$ in the oxide film. 


\section{References}

[1] G. Sandrock, J. Alloy. Compd., 293-295, 877-888 (1999).

[2] B. Sakintuna, F.L. Darkrim, M. Hirscher, Int. J. Hydrog. Energy, 32, 1121-1140 (2007).

[3] L. Schlapbach and A. Züttel, Nature, 414, 353-358 (2001).

[4] C. Corgnale, B. Hardy, T. Motyka, R. Zidan, J. Teprovich and B. Peters, Renew. Sust. Energ. Rev., 38, 821-833 (2014).

[5] C. Corgnale, B. Hardy, T. Motyka, R. Zidan, J. Teprovich and Brent Peters, Renew. Sust. Energ. Rev., 38, 821-833 (2014).

[6] R.C. Bowman, and B. Fultz, MRS BULLETIN, 27, 688-693 (2002).

[7] M.V. Lototskyy, V.A. Yartys, B.G. Pollet and R.C. Bowman Jr., Int. J. Hydrog. Energy, 39, 5818-5851 (2014).

[8] G.D. Sandrock and P.D. Goodell, J. Less-Common Met., 73, 161-168 (1980).

[9] J. J. Reilly and R. H. Wiswall, Inorg. Chem. 13, 218 (1974).

[10] S.M. Lee and T.P. Perng, J. Alloy. Compd., 177, 107-118 (1991).

[11]R.R. Jeng, S.L. Lee, C.W. Hsu, Y.P. Wu and J.C. Lin, J. Alloy. Compd., 464, 467-471 (2008).

[12]I. Yamashita, H. Tanaka, H. T. Takeshita, N. Kuriyama, T. Sakai and I. Uehara, J. Alloy. Compd., 253-254, 238-240 (1997).

[13] Y. Tanaka, M. Nakai, T. Akahori, M. Niinomi, Y. Tsutsumi, H. Doi and T. Hanawa, Corrosion Sci., 50, 2111-2116 (2008).

[14] Y. Zeng, J.J. Noël, P.R. Norton and D.W. Shoesmith, J. Electroanal. Chem., 649, 277-285 (2010).

[15]M. Morishita, M. Chikura, Y. Ashida, M. Morinaga, N. Yukawa and H. Adachi, J. Jpn. Inst. Metals, 55 720-726 (1991).

[16] S.J.B. Corrigan, J. Chem. Phys, 43, 4381-4386 (1965).

[17]M. Nakagawa, Y. Matono, S. Matsuya, K. Udoh and K. Ishikawa, Biomater., 26, 2239-2246 (2005).

[18]R. Kondo, Suyalatu, Y. Tsutsumi, H. Doi, N. Nomura and T. Hanawa, Mater. Sci. Eng. CMater. Biol. Appl., 31, 900-905 (2011). 